Arteterapia. Papeles de arteterapia y educación para inclusión social ISSN: $1886-6190$

\title{
DE MI FOR YOU. Proyecto artístico de colaboración internacional entre personas afectadas por trastorno mental grave
}

\author{
Laura Figueroa Sebastián ${ }^{1}$; Virginia Pérez Pastor²
}

Recibido: de marzo de 2016 / Aceptado: 13 de junio de 2016

Resumen. El trabajo artístico colaborativo internacional consistió en generar un canal de comunicación y de creación entre dos grupos de participantes afectados por trastorno mental grave y usuarios de servicios de atención a la salud mental ubicados en países diferentes: un grupo situado en Calatayud, Zaragoza (España) y otro en Londres (Inglaterra).

El marco de trabajo estuvo basado en la libertad de creación y la flexibilidad partiendo de una sencilla sugerencia apoyada en la "Teoría de las cinco pieles" del artista austriaco F. Hundertwasser.

Palabras clave: Arte outsider; Mail Art; Arte comunitario; Empoderamiento; Colaboración Internacional; Arteterapia; Inclusión Social.

\section{[en] DE MI FOR YOU. Artistic project of international collaboration between people affected by severe mental disorder}

\begin{abstract}
The international and collaborative art project consisted in producing a communication and a creation channel between two groups of participants affected by acute mental disorders who are clients of mental health services placed in diferent countries: one group is located in Calatayud, Zaragoza (Spain) and the other in London (UK).

The framework was based on a creative, free and flexible setting founded on a simple suggestion which was supported with the artist Hundertwasser theory of the "five skins".

Keywords: Outsider art; Mail Art; Community Art; Empowerment, International Collaboration; Art Therapy; Social inclusion.
\end{abstract}

Sumario. 1. Introducción teórica; 2. Arte como herramienta de intervención en salud mental e inclusión social; 3. Metodología y desarrollo del proyecto; 4. Exposiciones; 5 Evaluación; 6. Conclusiones; 7. Referencias bibliográficas.

1 Universidad de Zaragoza. Trabajadora Social (Universidad de Zaragoza) y Terapeuta Familiar (Máster en Intervención Familiar y Sistémica, Universidad de Zaragoza). Actualmente trabaja como Trabajadora Social en Fundación Rey Ardid (Centro de rehabilitación y apoyo psicosocial para personas afectadas por trastorno mental grave) en Calatayud, Zaragoza.

laufiguese@gmail.com

2 Universidad de Girona / Universidad Miguel Hernández Arteterapeuta (Máster integrativo de Arteterapia de la Universidad de Girona) y Licenciada en Bellas Artes (Universidad Miguel Hernández). Actualmente trabaja como Coordinadora de Actividades en una unidad hospitalaria de rehabilitación para adultos afectados por trastorno mental grave, Servicio Nacional de Salud (NHS) en Londres, Inglaterra. virginiaperezpastor@gmail.com 
Cómo citar: Figueroa Sebastián, L; Pérez Pastor, V. (2016) DE MI FOR YOU. Proyecto artístico de colaboración internacional entre personas afectadas por trastorno mental grave, en Revista de Arteterapia 11, 55-66.

\section{Introducción teórica}

El ámbito de la atención a la salud mental, y en concreto al trastorno mental grave, ha cambiado de manera significativa en los últimos años, promoviendo la aparición de recursos intermedios rehabilitadores que persiguen objetivos más allá de la mejoría clínica. Su objetivo es que el usuario recupere un nivel óptimo funcional para vivir de la forma más autónoma posible en la comunidad y que consiga una integración social justa y, en definitiva, una buena calidad de vida.

El arte, específicamente los talleres artísticos, el arteterapia y el arte marginal, ha tenido y sigue teniendo un papel importante en la evolución de la psiquiatría. En los años 20 dadaistas y surrealistas ya comenzaron a interesarse por el inconsciente, por los textos de Freud y por la salud mental pero fue en 1949 cuando se celebró la primera exposición del Art Brut, término acuñado por Jean Dubuffet. El concepto de psiquiatría y su intervención en el campo de la rehabilitación social ha cambiado mucho desde entonces, sobre todo después de la aparición de movimientos como el conocido Anti psiquiatría, que concebido y definido por el inglés David Cooper en su trabajo Psiquiatría y anti psiquiatría publicado en 1967 o el movimiento Psiquiatría democrática fundado por el psiquiatra italiano Franco Basaglia en el mismo periodo.

Hoy en día se precisa de equipos multidisciplinares capaces de dar atención a los diferentes aspectos de la vida del paciente de forma integral. Se diseñan programas y proyectos complementarios para favorecer la recuperación en todas las áreas que intervienen en el funcionamiento de la persona evitando, en lo posible, recaídas y recuperando funciones cognitivas y habilidades sociales deterioradas. Participar en estos programas y proyectos supone que la persona aprenda a identificar y convivir con los síntomas y posibles limitaciones que la propia enfermedad conlleva, en otras palabras, les ayuda a responsabilizarse de su afección.

A diferencia del modelo médico basado en el tratamiento de síntomas clínicos y en el que se trabaja a partir de la relación médico-paciente, el modelo psicosocial aborda la enfermedad desde las diferentes dimensiones con las que se relaciona el sujeto, además de colocar a los profesionales en un rol de colaboración y acompañamiento hacia la recuperación.

Esta perspectiva sitúa al paciente en un lugar activo y primordial en su rehabilitación. Por ello el enfoque técnico debe basarse en minimizar las discapacidades y variar la respuesta social que provoca la minusvalía, capacitando al usuario mediante entrenamientos específicos, o bien proporcionando soporte para lograr un funcionamiento óptimo (IMSERSO, 2007).

La Declaración de la Oficina Regional para Europa de la OMS Empoderamiento del Usuario de Salud Mental 2010, determina que empoderar a nivel individual es un proceso de toma de control y responsabilidad de sus actuaciones que tienen como propósito alcanzar la totalidad de su capacidad. Este proceso consta de cuatro dimensiones (autoconfianza, participación en las 
decisiones, dignidad y respeto y pertenencia y contribución a una sociedad más plural). Los talleres artísticos, gracias a su formato de laboratorio de creación participan de estas mismas dimensiones y de otras que ayudarán a los participantes para:

- Mejorar la autopercepción de las personas afectadas por enfermedad mental.

- Facilitar la visibilización de sus capacidades y competencias.

- Promover el empoderamiento de la personas, tanto a nivel individual como colectivo, a través de la libre creación.

- Fomentar la inclusión social y minimizar la estigmatización del colectivo de salud mental.

- Aumentar el interés y la relación con la realidad y el entorno.

- Desarrollo de nuevas estrategias de pensamiento.

- Tolerancia de la frustración.

- Mejora de las capacidades de comunicación y la empatía.

- Mejora de la planificación, concepción del tiempo y el espacio así como de las habilidades motoras.

\section{Arte como herramienta de intervención en salud mental e inclusión social}

"Completar y devolver, por favor". Con esta misiva comenzó la andadura del Mail Art de la mano del artista Ray Johnson a finales de los años cincuenta. El Mail Art o arte de correspondencia es un sistema propio y alternativo para la difusión de la obra, algo que puso y sigue poniendo en entredicho las concepciones de institución museística, el arte como obra acabada, la propiedad privada y el valor comercial o la democratización del arte. A su vez se promueve con esta práctica la libertad de acción y consecuente falta de reglas así como el uso de materiales y técnicas inéditos.

El Arte Outsider comparte todas estas características con el Mail Art y añade otra, la franqueza de sus obras, que suelen generar en el público una respuesta emocional intensa a pesar de la dificultad de comunicación ordinaria de sus creadores. La forma instintiva y personal en que Hundertwasser usa el color y la composición podrían resultar también parecidas a la espontaneidad y práctica, aparentemente inconsciente, del Arte Bruto o Arte Outsider.

La repetición o el estereotipo son algunas de las características que se observan en este tipo de arte, y precisamente en este proyecto se intensifica su presencia debido a la propia metodología que hace uso de la re-interpretación de obras ya existentes. Es interesante cómo algunos de los participantes se inclinan por usar las mismas imágenes para ser intervenidas, o cómo la misma persona puede realizar un trabajo recurrente en cuanto a forma, color, rasgo, símbolo o gesto. Podría tratarse de una forma de reestructurar una realidad fragmentada por las diferentes patologías de salud mental que sufren los usuarios del taller. 


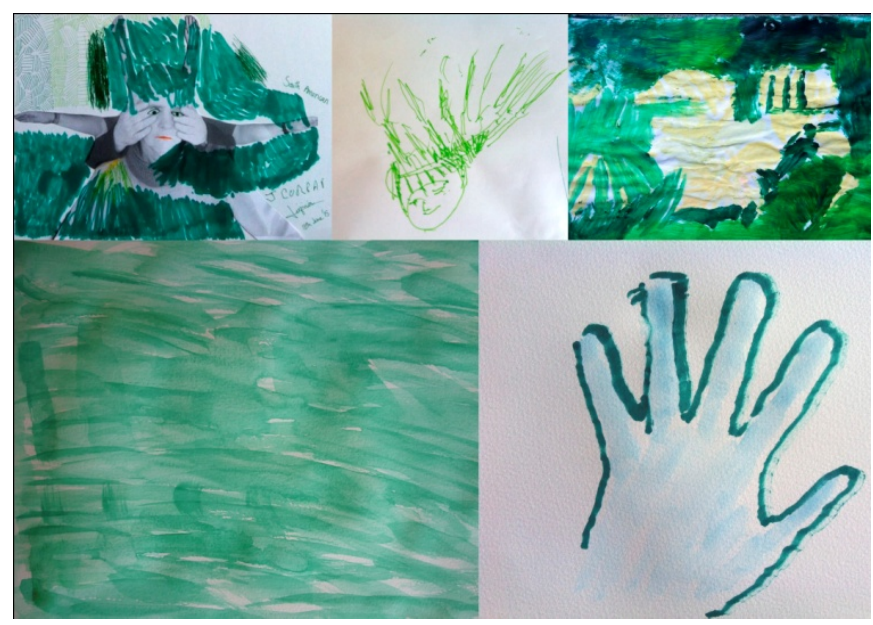

Figura 1. Repetición1: Imágenes realizadas por la misma persona en diferentes estadios del proyecto.

Por otro lado, la repetición de acciones, imágenes o discursos provoca estados alterados de conciencia y por ello satisfacción y/o alivio. Según Csikszentmihalyi (1997) se trata de una experiencia placentera del fluir que conlleva una afirmación de la identidad. Jung (Íbidem, 2010), en cambio, lo interpreta como un mecanismo para acceder al inconsciente colectivo. De cualquier manera la creación nos coloca a menudo a mitad de camino entre lo posible y lo imposible, la realidad y la imaginación. Cuando creamos, nos creamos a nosotros mismos y nuestra particular visión del mundo, y cuando mostramos nuestra obra a los demás nos mostramos con ella. El arte se convierte pues en catalizador y propulsor de infinidad de posibilidades humanas en la relación con su entorno. El arte y la creación se convierten en oportunidades de desarrollo personal e integración social.

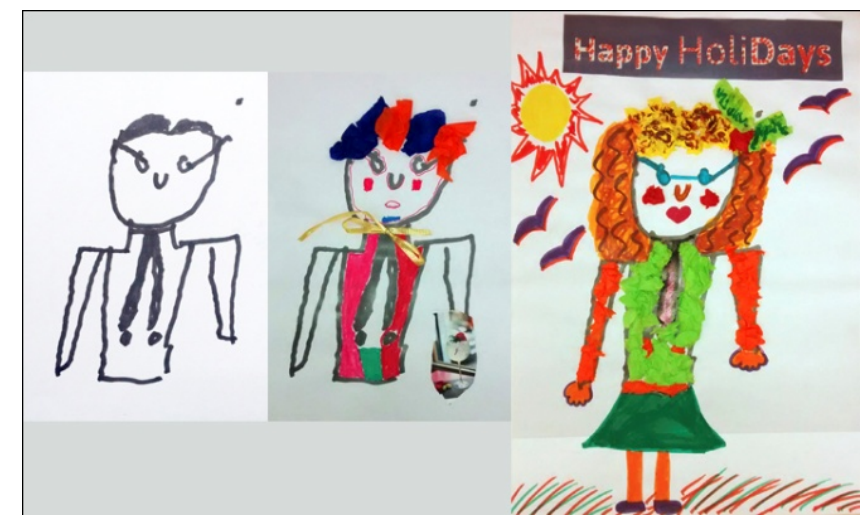

Figura. 2. Repetición 2: Imagen original realizada por uno de los participantes en Londres e intervenida varias veces en Zaragoza mediante diferentes procedimientos artísticos por diferentes personas. 
De mi for you hace uso de las nuevas tecnologías como herramienta de trabajo. En los talleres artísticos ubicados en Centros Hospitalarios abunda el uso de técnicas artísticas como la pintura o el dibujo, seguido por la escultura y la artesanía. La fotografía o el vídeo se utilizan normalmente como métodos de documentación del proceso más que como técnicas artísticas en si mismas. A diferencia de otras técnicas artísticas, la fotografía, coloca al objeto/sujeto presentado como algo real, en un lugar y un tiempo determinado. Las fotografías familiares o las instantáneas personales son valiosas e importantes para estimular el proceso creativo, el uso de las metáforas y el contacto con las emociones (Rossi, 2014). Es por esto que se puede establecer una conexión más íntima, algo que ha ocasionado ciertas dificultades. Si el entorno no existe en sí mismo, no es un mundo físico provisto con características diferentes sino mas bien un concepto definido por la relación entre el observador y la realidad observada que juntos forman un sistema complejo (teoría de los sistemas, Gibson, 1986) entonces, en caso de que la percepción esté alterada por la enfermedad mental, provocará cierto rechazo de algunas imágenes demasiado reales. De mi for you hace uso de las obras creadas por un colectivo desconocido para su posterior transformación. Esto puede generar cierto rechazo dependiendo del grado de patología que sufran los individuos resultando que: cuando los síntomas psicóticos no se encuentran activos resultará más fácil conectar con el trabajo del otro. En cambio resultará más difícil empatizar con el otro si el estado mental es inestable.

La utilización de herramientas artísticas en el campo de la rehabilitación psicosocial no es un fin en sí mismo, no tiene por qué perseguir un fin educativo, sino que resulta un medio más para contribuir a los objetivos de recuperación de la persona afectada de un problema de salud mental, entre los que destacan ante todo la promoción de la autonomía y el desarrollo personal. Lo que realmente importa es el proceso creativo a través del cuál la persona pueda aprender a enfrentarse al conflicto y a la frustración, elegir entre una técnica u otra o planificar las tareas entre otras cosas y más allá de la calidad estética del resultado final. Será esencial en este tipo de prácticas, además de realizar un trabajo directo con el colectivo sujeto a la rehabilitación mental, promover el cambio social a través de la exhibición de las obras o su publicación en redes sociales, generando así conexiones con otros ámbitos, favoreciendo el reconocimiento de las capacidades y reduciendo el aislamiento del colectivo citado. Citado por Palacios, tenemos la responsabilidad de trabajar por una cultura más accesible, participativa, descentralizada y que refleje las necesidades y particularidades de las diferentes comunidades (Palacios, 2009). El arte comunitario o arte de la comunidad, surgido en Reino Unido y EEUU en los años 70 como respuesta a una preocupación y un cuestionamiento de los valores sociales de la época, ya comenzó a utilizar los procesos creativos y los proyectos artísticos como herramientas para el cambio social. Si el arte comunitario es algo, es la manifestación de una ideología (Morgan, 1995:18) que coloca a la creatividad como una potencia de transformación social. Mientras que en Reino Unido los artistas realizaron sus trabajos dentro de organismos públicos como el London Health Department para generar e incorporar ideas creativas a los problemas existentes, en EEUU el arte comunitario se centró en la inclusión social de comunidades que sufrían supresión y desadaptación a través de la creación de murales y siempre en contacto directo 
con el vecindario y sus habitantes que tomaban parte activa en las decisiones y la consecución del trabajo. Kester (2004) propone el arte dialógico profundizando sobre el papel del artista como sujeto en relación con otros, potenciando el intercambio, el diálogo, la comunicación entre artista y el público. De mi for you coloca a los creadores en relación con otros; que son, como ellos, sujetos transformadores y transformados al producirse un intercambio, un diálogo entre ellos y con el público.

El papel del taller artístico, del artista y del arteterapeuta dependerá del marco de la institución en que se realice. Por un lado encontramos espacios artísticos y no terapéuticos (asociaciones comunitarias, artísticas, vecinales o familiares) donde normalmente los responsables del trabajo son artistas y menos frecuentemente serán arteterapeutas. Por otro lado tenemos espacios terapéuticos (centros de día, unidades hospitalarias agudas, ambulatorios, centros de rehabilitación o centros para ex-pacientes) donde normalmente encontramos equipos multidisciplinares de profesionales de la salud. La diferencia también dependerá del grado en que el arte o el rol del arteterapeuta son considerados estos dos espacios. En España, a diferencia con Inglaterra, el rol del arteterapeuta no está incluido en espacios terapéuticos como por ejemplo los hospitales psiquiátricos de una manera normalizada y regulada. Esto será fundamental a la hora de poder unificar enfoques y fortalecer el papel del arte en los psiquiátricos y otros espacios terapéuticos o no terapéuticos así como para realizar un registro y una documentación de los talleres artísticos y su correspondiente evaluación.

\section{Metodología y desarrollo del proyecto}

El arte es un modo excelente de tratar con el cambio, con la capacidad de repensar la identidad, de trabajar los vínculos personales e interpersonales, nuevas formas de comprender el mundo y los seres humanos. El arte es un área de posibilidades y libertad (López Fdz. Cao, 2012) especialmente cuando los artistas no han estado en contacto con el arte académico. Hundertwasser no solo no cree en la Academia sino que opina que de alguna manera destruye la posibilidad del ser: -si no te has encontrado a ti mismo o si te has perdido y quieres recuperarte, la Academia es el peor lugar posible. Todo el mundo debería empezar en el punto donde todavía era uno mismo, antes de ser inundado, antes de ser alienado por su casa, por el sistema de crianza, por la escuela, por las diferentes costumbres de nuestra civilización(Hundertwasser. F, 1982). La mayoría de los individuos que han participado en el proyecto no han tenido apenas conexión con el arte y mucho menos con la Academia, por ello sus creaciones tienen esa tendencia estética cándida y aniñada.

El encuadre metodológico utiliza la teoría de las cinco pieles de F. Hundertwasser para dar forma al proyecto y su posterior exhibición (epidermis, la ropa, el hogar, el entorno social y la identidad y el entorno mundial, ecología y humanidad). El taller de Arteterapia ECO del Complejo Socio-sanitario de La Merced en Guadalajara o el Taller de Arte ECO en Madrid han trabajado también a partir de obras de artistas como Miró, Picasso, Maruja Mallo o Hundertwasser utilizando diversas técnicas y procedimientos artísticos como la pintura, el dibujo, el collage. En estos grupos también se ha incorporado recientemente el uso de la fotografía y el vídeo. 
De mi for you combina procedimientos artísticos con técnicas de investigación social: el arte dialógico y participativo (incluyendo el Mail Art) encaja perfectamente con el método de investigación acción participativa (IAP), que se basa en un análisis subjetivo y crítico de la realidad a través de la participación de las personas implicadas. Estos dos métodos están orientados a generar procesos trasformadores y de cambio social. Se trata de incentivar el potencial creativo y fomentar la expresión libre. Para ello se brinda poca orientación y consejo a los artistas.

El proyecto comienza de forma paralela en las dos entidades sociales colaboradoras; una es un piso tutelado para adultos afectados con trastorno mental grave perteneciente a la compañía de apoyo y cuidado Look Ahead en Londres. Los individuos asociados a esta entidad viven en la comunidad aunque han pasado grandes periodos de tiempo en hospitales psiquiátricos y unidades de rehabilitación, quizá por esto sus habilidades sociales se han visto reducidas y parecen estar más institucionalizados. No han tenido apenas experiencias artísticas. En Inglaterra no existen centros de día tal y como los conocemos en España así que la inclusión social de estas personas resulta más dificultosa y ha de contar con agencias privadas y externas que cumplan con esta labor.

La otra entidad colaboradora es una unidad de rehabilitación psicosocial de personas afectadas de trastorno mental grave: perteneciente a la Fundación Ramón Rey Ardid en Calatayud, Zaragoza. Los usuarios de este centro tienen más experiencia con la práctica artística puesto que llevan realizando talleres y proyectos creativos desde el año 2011.

El proceso de trabajo del proyecto puede dividirse en tres fases diferenciadas:

$\mathbf{1}^{\text {a }}$ fase: presentación de la propuesta a los usuarios de cada servicio bajo las premisas de flexibilidad y libertad de creación. Durante veinte sesiones se emplearon las cinco pieles de Hundertwasser para generar grupos de debate y discusión acerca de la representación de esas cinco pieles y su conexión personal con el significado de las mismas para cada uno de los participantes.

La primera piel, la epidermis, es la zona membranosa más cercana al yo interior; la que encarna la desnudez del hombre y del pintor (Hundertwasser. F, 1967). La ropa se convierte en una llamada a la creatividad y la autenticidad bajo la mirada del artista, quien critica los dictados de la moda, el anonimato y la uniformización. El hogar, tal y como se concibe en la sociedad, es rectilíneo y poco tiene que ver con la naturaleza por eso él propone una arquitectura que esté en armonía con el entorno ya que arte, dice, es un puente entre el hombre y la naturaleza y el acto creativo es un acto religioso. La cuarta piel, la identidad, se basa en la idea de que cada ser humano y su conexión con la sociedad es diferente, dependerá de factores como la nacionalidad y la cultura de los sujetos. El mundo y el medio ambiente ocupan la última piel y su mayor preocupación por la ecología y por vivir en armonía con la naturaleza.

Tras haber reflexionado sobre los cinco conceptos y el significado personal que conforma parte de su identidad, los usuarios del taller pasaron a generar representaciones de esos conceptos a través de diferentes técnicas como la fotografía, el dibujo, el collage, la escritura, el assemblage, la acuarela, la acción poética o la pintura. El Arteterapia, como Rodríguez (2005) señala, posibilita 
oportunidades para plasmar las vivencias o recuerdos. Esto proveerá satisfacción y mejoría aun cuando no se modifique el sustrato fisiológico de la enfermedad.

$2^{\mathbf{a}}$ fase: las obras originales fueron fotografiadas y posteriormente intercambiadas por correo electrónico entre los usuarios de los centros de Londres y Calatayud. Las imágenes fueron impresas y todos los participantes tuvieron la oportunidad de observar la visión del otro sobre el mismo concepto que ellos habían trabajado con anterioridad, pudieron observar la diferencia cultural, la calidad artística de las obras y la transmisión de sensaciones de las mismas. La realización de obras artísticas facilita la cohesión grupal y la relación interpersonal, incrementa los niveles de satisfacción y placer (Pascal y Ávila 2007).

$3^{\mathbf{a}}$ fase: una vez las nuevas imágenes fueron recibidas e impresas, los participantes intervinieron sobre ellas o crearon nuevas versiones a través de diferentes técnicas artísticas, formando nuevas obras con significados compartidos que conforman un gran cadáver exquisito.

- Eso es la verdadera creación. Algo que viene a ser uno mismo. Uno puede copiar cosas. Por copiar quiero decir no solo fotografiar o dibujar, de manera parecida a la que Durero hizo cuando dibujó césped o un conejo... Por copiar quiero decir también cuando alguien copia tus sueños, el mundo interior de uno... Alguien tiene una visión, alguien ve algo con sus propios ojos y quiere eternizarlo. Eso también es copiar.- (Hundertwasser. F, 1982). 1

Ponerse en lugar del otro, saber lo que siente o lo que puede pensar es una oportunidad para entender la complejidad del mundo y de uno mismo. Los participantes analizan la situación, los problemas y los recursos (teoría). Por otro lado se generan mecanismos de mejora a través del aprendizaje, toma de conciencia crítica sobre la realidad, empoderamiento, movilización colectiva y acción transformadora (praxis). Se generan nuevos debates sobre la conformación de la identidad del ser humano, la enfermedad mental, su sentido en la sociedad actual y el estigma social que todavía incita.

El intercambio cultural ha resultado ser un valor añadido al proceso creativo dado que los participantes pudieron identificarse como colaboradores mutuos desde sus diferentes valores, percepciones y creencias, otorgando a las obras finales un significado doblemente enriquecido por ambas perspectivas.

\section{Exposiciones}

Desde que en 1967, de la mano de Dubuffet, se celebrase la exposición Art Brut en el Museo de las Artes Decorativas de Paris con más de 700 piezas, los artistas Outsider han ganado reconocimiento y algo más de visibilización. Otro paso importante se dio en 1984 con la exposición el Salon des Independants en Paris, desde aquel momento el arte de la Academia quedó desafiado. En 1992/93 Los Angeles Museum of Art acogió la muestra Parallel Visions que combinaba el trabajo de artistas reconocidos y otros marginales como Antonin Artaud, Ferdinand Cheval, Henry Darger, Howard Finster, Madge Gill, Martin Ramirez, P. M. Wentworth, Adolf Wlfli y Joseph Yoakum. Esta misma exhibición itinerante pudo contemplarse en otras instituciones como el Museo Reina Sofía de Madrid, en Basilea y en Tokio. En la actualidad algunos artistas marginales como Yayoi 
Kusama, Tsoku Maela, Juditt Scott o Bobby Baker han logrado exponer sus obras en grandes galerías e incluso convertirse en populares artistas contemporáneos. El Foro 2x2 Outsider Art realizado en 2009 en la ciudad alemana Münster expuso muestras del trabajo realizado en talleres y estudios artísticos y/o arteterapéuticos de diferentes países europeos como Alemania, Finlandia, Italia, Austria.

The Hundertwasser not profit foundation (2013) Tape-recorded letter by Hundertwasser to the students of the Master School at the Acadamy of Fine Arts in Viena (1982). http://www.hundertwasser.com/

Suiza, Noruega y España. Galeristas, arteterapeutas, psiquiatras y personalidades del área museística como la Dra. Lisa Niederreiter debatieron en un ciclo de conferencias y mesas redondas sobre el desarrollo actual del arte outsider.

La lucha contra el estigma asociado a falsos mitos y perjuicios se hace cada día más necesaria para evitar la discriminación y la exclusión social. Por ello debemos generar espacios que originen cambios de perspectiva visibilizando las capacidades y competencias de los individuos, garantizando una ciudadanía plena.

Las obras generadas en el proyecto De mi for you fueron expuestas en octubre de 2015 en el centro Espacio Visiones (Zaragoza), espacio creativo en la comunidad para personas afectadas por trastornos mentales y que normalmente se encuentran asociadas a alguno de los recursos de salud mental de la Fundación Rey Ardid o a cualquier otro organismo público (IAS, SAS).

En diciembre de 2015 varios participantes del proyecto participaron también en el encuentro ciudadano Mercado del 13 con el fin de dar a conocer el proyecto y sus beneficios aunque esta vez mostraron solo una selección de obras. Esta iniciativa solidaria realiza mercados efímeros e itinerantes, talleres creativos de arte, moda y gastronomía en espacios singulares. Organiza eventos sostenibles y colaborativos en los que aplica conceptos de la economía circular.

La participación en estos espacios, terapéuticos y no terapéuticos, potencia y facilita el empoderamiento de las personas afectadas por trastorno mental, dotándoles con un rol productivo y competente en la vida comunitaria y por tanto incluyéndoles en la sociedad de forma positiva.

El trabajo desde la arteterapia genera canales de reflexión, comunicación y desarrollo personal potenciando la proyección de aquellos objetos internos en el espacio externo en forma de obra artística. De esta forma los objetos internos se concretizan y por ello disminuye la percepción subjetiva y malestar de propio de la enfermedad. Esto fue reflejado en el estudio de una intervención artística realizado por Pascale y Ávila (2007) en una unidad de psiquiatría para adolescente.

La perspectiva del trabajo social, desde el rol de capacitador, aporta los valores de empoderamiento y promoción del cambio y desarrollo social, ayudando a los ciudadanos a encontrar los medios necesarios para su bienestar en su entorno social y construyendo para los individuos y grupos canales de mutuo entendimiento para la acción común (Friedlander, 1978). 


\section{Evaluación}

La comunicación intercultural, la experiencia individual y artística, la toma de decisiones, el trabajo en equipo, la relación con los materiales y procedimientos artísticos, el aprendizaje sobre la técnica, el análisis del entorno y las emociones, la construcción de nuevas visiones del mundo, la comunicación y la no estigmatización a través de la visibilización del trabajo en espacios artísticos han sido los objetivos marcados para observar el impacto tanto en los participantes del taller como en el público que visitó las posteriores exposiciones.

En Zaragoza los participantes mostraron un alto grado de colaboración e implicación personal con las distintas fases del proyecto. Pudo observarse semanalmente una asistencia continuada a los talleres durante todas las fases. La profesional responsable del taller asesoró y apoyó a los participantes aunque la mayoría de ellos se mostraban motivados desde el principio, presentaban iniciativa, independencia y ambición de experimentación con las técnicas y los materiales así como curiosidad por las obras ajenas.

En Londres el compromiso con el trabajo del taller fue complejo, los participantes necesitaron mucho apoyo por parte de la arteterapeuta sobre todo al inicio del proyecto. Más adelante algunos empezaron a mostrar iniciativa y asistencia continuada sin necesidad de ser convocados previamente por la coordinadora del proyecto.

Gracias a la presentación del proyecto en medios de comunicación autonómicos de radio y prensa escrita, las exposiciones de los trabajos en espacios artísticos gozaron de una elevada asistencia comunitaria así como un alto grado de cooperación y satisfacción por parte de los participantes y los espacios que acogieron las muestras. El interés local también se reflejó en las redes sociales donde los eventos se publicitaron.

Estos procesos de inclusión social confieren un enriquecimiento en el sentimiento de valía dentro de la sociedad así como una mejora de la autoestima para los participantes de los talleres. Por otro lado también generan el entendimiento, el respeto o la apreciación de las capacidades por parte de la comunidad en la que están inscritos.

En palabras de una de las participantes participando en una entrevista en la radio local SER Calatayud:

- ¿Cómo os sentisteis al trabajar las obras?-

- Al principio me sentí un tanto ridícula, me parecía una actividad demasiado sencilla, incluso infantil. Pero he comprendido que a veces las cosas más sencillas son las que más cuestan de ver, no les damos la importancia que tienen, y en realidad son las que nos unen a las personas, lugares y en general a toda la sociedad y nos ayudan a ponernos en el lugar de los demás. Cuando intercambiamos los trabajos me sentí integrada, acompañada, no estaba sola. Sentía a los compañeros de Londres a través de sus fotos, aunque no estaban ahí, de alguna manera sí estaban entre nosotros. 


\section{Conclusiones}

Para que la recuperación psicosocial de las personas afectadas por trastorno mental grave sea exitosa ha de contar con el apoyo de, no solo profesionales y/o familiares, sino de la sociedad y sus actores. La cultura, el arte, y sus agentes actúan perfectamente como contenedores capacitadores y por ello parte de su responsabilidad es educar a la sociedad en la inclusión.

Hemos de reflexionar sobre cómo generar espacios y actividades que visibilicen las capacidades de todos aquellos que no se consideren normalizados para que empiecen a serlo.

\section{Referencias bibliográficas}

Ander Egg, E. (1990). Repensando la investigación acción-participativa. Vitoria Servicio de publicaciones del gobierno vasco.

Ariadne (2012) Art of adaptation: manual of artistic tools for migrants. Project number: 510255-LLP-1-2010-1-FR-Grundtvig-GMP. Website: www.ariadne4art.eu

Asociación Madrileña de Reabilitacion Psicosocial, Instituto de Trabajo Social y Servicios Sociales. Asociación Guipuzcoana De Familiares Enfermos Psíquicos (2007) Modelo de centro de rehabilitación psicosocial. Madrid. Imserso.

Berman, L (1993) Beyond the smile: the therapeutic use of the photograph. London. Routledege.

Berst, C (2009) Art brut and the art market: evaluating the invaluable. Conferencia presentada en el foro " $2 \times 2$ Forum für Outsider Art". Kunsthaus Kannen, Münster.

Bishop, C (2006) Participacipation. London, Cambrigde. Whitechapel, The MIT Press.

Cooper, D. (1967) Psychiatry and anti-psychiatry. Tasvistock Publications LTD. London.

Dittborny Paulo Burscky, E. (2006) El arte postal en el arte contemporáneo. Revista virtual de arte contemporáneo. Fabiane Pianowskli.

Friendlander, W. A. (1978). Dinámica del Trabajo Social. México. Ed. Pax.

Título del original inglés

Hyland Moon, C. (2010) Materials \& Media in Art Therapy critical understandings of diverse artistic vocabularies. New York, Taylor \& Francis group.

Lopez Fdz Cao, M. (2015) Indicadores sobre prácticas comunitarias: algunas reflexiones. Papeles de arteterapia y educación artística para la inclusión social. Vol 10/2015 (págs.:209-234). Madrid.

Lopez y Martinez (2006) Arteterapia: conocimiento interior a través de la expresión artística. Madrid, Tutor S.A

OMS, Oficina Regional para Europa. (2010) Empoderamiento del usuario de salud mental. Copenhague. Oficina Regional para Europa.

Palacios, A (2009) El arte comunitario: origen y evolución de las prácticas colaborativas. Papeles de arteterapia y educación artística para la inclusión social. Vol. 4/2009 (págs.: 197-211). Madrid.

Pascale, P. y Ávila, N. (2007) Una experiencia de creatividad con adolescentes hospitalizados. Unidad de Psiquiatría de adolescentes del Gregorio Marañón. Arte, Individuo y Sociedad. 
Restany, P (2008) Happy Hundertwasser. Hundertwasser New York: Parkstone Press International. New York.

Restany, P (1998) The power of Art Hundertwasser: The Painter-King with the five skins. Switzerland. Taschen.

Rossi, O. (2014) Looks and images: video and photo therapy. Papeles de arteterapia y educación artística para la inclusión social. Vol 9/2014 (págs.:191-202). Madrid.

Sanchez de Serdio, A (2008) Prácticas colaborativas: el artista y sus socios invisibles. DHuarte, 3, 17-18. 